\title{
Plasma Spectroscopy Diagnostics of $\mathrm{V}_{2} \mathrm{O}_{5}$ at a Variable of Operating Power and Pressure With Radio Frequency Magnetron Sputtering.
}

\author{
Ibrahim K. salman ${ }^{{ }^{*}}$ \\ Mohammed K. Khalaf ${ }^{2}$ \\ Hanaa Eesa Jasim ${ }^{4}$
}

N.K. Hassan ${ }^{3}$

Received 6/5/2018, Accepted 2/9/2018, Published 17/3/2019

This work is licensed under a Creative Commons Attribution 4.0 International License.

\begin{abstract}
In this paper, we investigate the basic characteristics of "magnetron sputtering plasma" using the target $\mathrm{V}_{2} \mathrm{O}_{5}$. The "magnetron sputtering plasma" is produced using "radio frequency (RF)" power supply and Argon gas. The intensity of the light emission from atoms and radicals in the plasma measured by using "optical emission spectrophotometer", and the appeared peaks in all patterns match the standard lines from NIST database and employed are to estimate the plasma parameters, of computes electron temperature and the electrons density. The characteristics of $\mathrm{V}_{2} \mathrm{O}_{5}$ sputtering plasma at multiple discharge provisos are studied at the "radio frequency" (RF) power ranging from 75 - 150 Watt and gas pressure $(0.03,0.05$ and 0.007$)$ torr. One can observe that the intensity of the emission lines increases with increasing the sputtering power. We find that the electron temperature excess drastically from $0.95 \mathrm{eV}$ to $1.11 \mathrm{eV}$ when the emptying gas pressure excess from 0.03 to 0.05 Torr. On other hand excess electron temperature from 0.9 to $1.01 \mathrm{eV}$ with increasing sputtering power from 100 to 125 Watt, while the electron density decrease from $5.9 \times 10^{14}$ to $4.5 \times 10^{14} \mathrm{~cm}^{-3}$ with increasing sputtering power. and electron density decrease with increasing of pressure from $4.25 \times 10^{14}$ to $2.80 \times 10^{14} \mathrm{~cm}^{-3}$, But the electron density maximum values $5.9 \times 10^{14}$ at pressure 0.03 Torr.
\end{abstract}

Keywords: Electron Density, Electron Temperature, Magnetron Sputtering, Plasma Spectroscopy, $\mathrm{V}_{2} \mathrm{O}_{5}$.

\section{Introduction:}

The use of plasma for "material deposition" is vastly used in industrial process and technology, "Magnetron sputtering" is the anymore lower-class for thin films deposition (1). Noble gases are generally used to generate the plasma because they are inactive. Commonly, plasmas are properties by exogenous parameters such as radio frequency input power, pedestal siding, gas and pressure, flow rate. Anyway, saving these exogenous parameters does not retrofit adequate knowledge of the sputtering practicality. Further, the film construct and accretions ratio, is provided by achieving the internal plasma parameters. Many diagnostic techniques are used to show properties plasma such as "Langmuir probe", optical emitting spectroscopy (OES) and "mass spectrometry" (2).

\footnotetext{
${ }^{\mathrm{T}}$ Ministry of Science and Technology, Department of provincial affairs, Baghdad, Iraq.

${ }^{2}$ Ministry of Science and Technology, Center of Applied Physics, Baghdad, Iraq.

${ }^{3}$ Department of Physics, College of Education, Tikrit University, Tikrit, Iraq

${ }^{4}$ Department of Physics, College of Scientific, Tikrit University, Tikrit, Iraq

*Corresponding author: akskalj.s73@gmail.com
}

Among these techniques, "Langmuir probe" is widely used to gauge plasma parameters like "electron density" $\left(\mathrm{n}_{\mathrm{e}}\right)$, "ion density" $\left(\mathrm{n}_{\mathrm{i}}\right)$, "electron temperature" $\left(\mathrm{T}_{\mathrm{e}}\right)$, etc. in low-pressure glow discharges. Also among the same techniques, there is "Optical emission spectroscopy" (3). This technique is based on the measurement of the light pattern transmitted by the plasma because it distinguishes the plasma properties. Radiation is the result of the interaction of the electron or ions with other plasma molecules. Four types of this plasma were proposed by MC Whiter, which depends on the electron interaction mechanism. Many of the methods to "electron temperature measurement" can be reached, these are $(4,5)$ :

1) The density ratio read between the lines.

2) The ratio of line density to the connected string.

3) The intensity of the two parts of the connection. The first pattern is used in this study for the valuation of the suggesting "electron temperature" in the (Ar) DC glow discharge. The intensity of these spectral stripe depends on $\left(\mathrm{KT}_{\mathrm{e}}\right)$, and always proportional to the resident's density of fervid states. Thence, $\left(\mathrm{KT}_{\mathrm{e}}\right)$ it could be determined using these 
spectral stripe intensities and "Boltzmann plot" equation (6):

$$
K T_{e}=\left[\ln \frac{I_{1} \lambda_{1} g_{2} A_{2}}{I_{2} \lambda_{2} g_{1} A_{1}}\right]^{-1} \times\left(E_{2}-E_{1}\right) \ldots \ldots
$$

The indices number 1 and 2 transmit to the first and second spectral stripe, $\mathrm{I}$ is the intensity, $\mathrm{K}$ is the "Boltzmann constant", $\mathrm{g}$ is the statistical weight, $\mathrm{E}$ is the excited case energy and $\mathrm{A}$ is the transition probabilistic. "The Boltzmann plot" manner is only proper if the evacuation plasma under study is in "complete local thermodynamic equilibrium" (LTE). In this spectrum, the argon sent outa stripe observed in the scope of 200-900 nm and $\mathrm{kT}_{\mathrm{e}}$ determine by selecting two Ar-I spectral stripes. In a titration, the E, $\mathrm{g}$ and $\mathrm{A}$ for choices stripe is taken from the National Institute of Standards and Technology NIST "Atomic Spectra Datasheet" (6, $7)$. The $n_{e}$ can determine using the near intensities of atomic and ionic spectral lines in "Boltzmann Saha equation" (8).

$n_{e}=\left[\frac{\left(2 \pi m k T_{e}\right)^{3 / 2}}{h^{3}}\right]\left[\frac{2 A^{+} g^{+} \lambda^{o} I^{o}}{A^{o} g^{o} \lambda^{+} I^{+}}\right] e^{\left[\frac{-\left(E^{+}-E^{o}+E_{i}^{o}-\Delta E_{i}\right)}{k T_{e}}\right]}$

Where, $(0,+)$ include the ionized atoms and neutral, $E$ is the energy of the emissive echelons, $E_{i}{ }^{0}$ is "the ionization energy" of the different atoms and $\Delta \mathrm{Ei}$ is the lower of ionization energy (9). In this study, we focus to investigate the plasma parameter of "magnetron sputtering plasma" using $\mathrm{V}_{2} \mathrm{O}_{5}$ target and its deposited $\mathrm{V}_{2} \mathrm{O}_{5}$ thin film.

\section{Materials and Methods:}

The main parts of the clogged plasma system are shown in Fig.1. Our work, $\mathrm{V}_{2} \mathrm{O}_{5}$ films were by the RF magnetron system (CRC600 CO. Manufactured in the USA). Films are placed on the glass base with changing powers. Glass slides were cleaned sequentially in the ultrasound course with ethanol and acetone. Finally, rinse with distilled water and come out. The spray chamber leaves the base pressure $3 \times 10^{-5}$ torr using the turbine and the mechanical pump mixture before deposition. Before deposition of $\mathrm{V}_{2} \mathrm{O}_{5}$ films, target $\mathrm{V}_{2} \mathrm{O}_{5}(99.99 \%$ pure and diameter $5 \mathrm{~cm}$ ) in a pure argon atmosphere for 15 minutes to remove the oxide on the target face. Deposition of $\mathrm{V}_{2} \mathrm{O}_{5}$ used "sputtering RF system" in pure gas $(99.9 \%)$ with pressure $\left(3 \times 10^{-2}, 5 \times 10^{-2}\right.$ and
$7 \times 10^{-3}$ torr), with various strengths $(75,100,125$, and 150 watts), respectively.

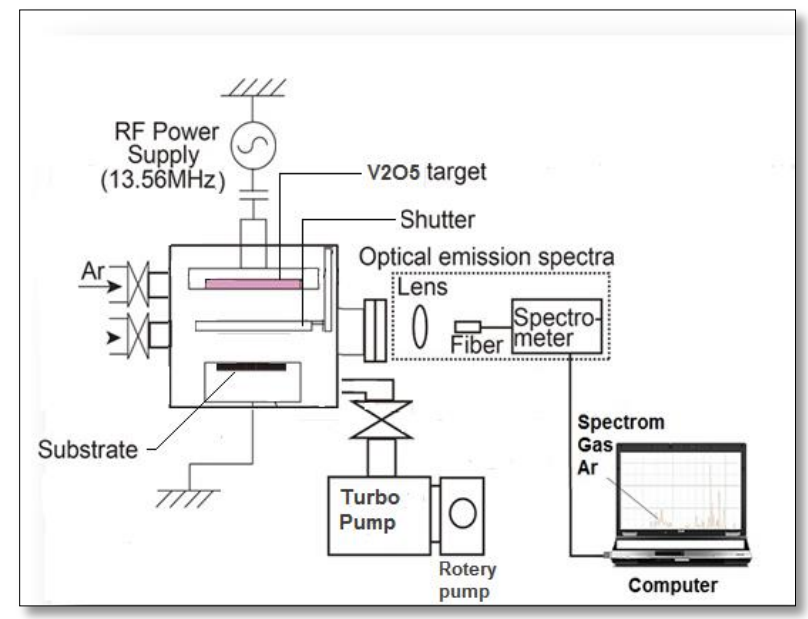

Figure 1. Graphical diagram of the setup used in this study.

\section{Results and Discussions:}

The emission spectra of argon plasma produced between electrodes at different RF power (75, 100, 125 and 150 Watt), are shown in Fig. 2. The intensity of two lines, one for $\mathrm{Ar} I$ at wavelength $(750.37 \mathrm{~nm})$ and the other for ArII at wavelength $(434.5 \mathrm{~nm})$ identical with NIST data, were chosen to estimate electron temperature by using lines intensity ratio method equation (1), NIST data, upper level energies, statistical weights (g) and transition probabilities(A), is listed in Table 1 .

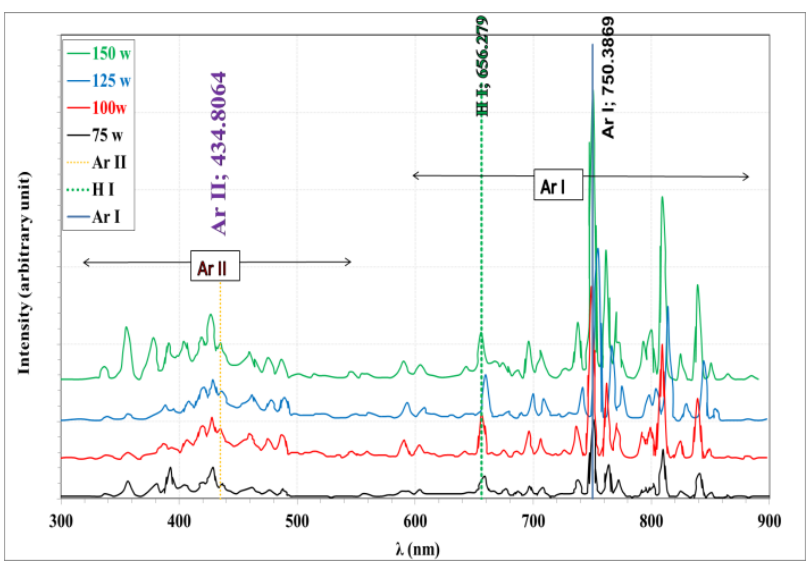

Figure 2. The emission spectra for plasma argon at different sputtering power.

Table 1. Values of transition probability, upper energy level and statistical weight that used to calculate $T_{e}(10)$.

\begin{tabular}{cccccccc}
\hline \multicolumn{2}{c}{$\begin{array}{c}\text { Wavelength } \\
(\mathrm{nm})\end{array}$} & \multicolumn{2}{c}{$\begin{array}{c}\text { Transition probability } \\
\mathrm{A},(\mathrm{S}-1)\end{array}$} & \multicolumn{2}{c}{$\begin{array}{c}\text { Statistical } \\
\text { weight } \mathrm{g}\end{array}$} & \multicolumn{2}{c}{ Upper energy level E, (eV) } \\
\hline ArI & ArII & $\mathrm{A}_{1}$ & $\mathrm{~A}_{2}$ & $\mathrm{~g}_{1}$ & $\mathrm{~g}_{2}$ & $\mathrm{E}_{1}$ & $\mathrm{E}_{2}$ \\
750.37 & 434.5 & $4.45 \mathrm{e}+07$ & $1.171 \mathrm{e}+08$ & 6 & 3 & 11.82807106 & 14.68065021 \\
\hline
\end{tabular}


As a appears in Table 1, the lower agitation energies for the argon lines are relatively high, $>11.8 \mathrm{eV}$ for Ar I.This refers to the emission of argon lines adoption on the presence of electrons in the plasma. An exception is that some Ar lines can also outrage efficiently from the Ar "metastable levels". Evidently, the energy required for excitation is less than that required for ionization because the electron of a stir atom does not remove completely from this atom. For example, the stirring energy of argon atoms is $11.8 \mathrm{eV}$ while the ionization energy is $14.6 \mathrm{eV}$. Besides, the stirring energy should be greater than or equal to the energy of the electronic case in order for the excitation to $\operatorname{occur}(7,11)$.

Figure 3. represents the variation of intensity for $(750.37 \mathrm{~nm})$ line and $(434.5 \mathrm{~nm})$ line respectively as a function of the RF Sputtering power at $3 \times 10^{-2}$ torr. It is clear that intensity of $\mathrm{Ar}$ I increases from (47.7 to 74.5) with the increasing rf power. This is mainly due to the strong impact of the electron density on the ionization process: higher power means higher electron density which results in more ionized atoms. On the other hand, there are a large number of single-ionized argon lines (Ar II) emitted from the argon spectrum for each discharge technique. The intensity of the Ar II lines reflects relative population among different energy levels of Argon ion, thus dependent on discharge Conditions: Gas pressure, discharge current and/or Input power rf. These results are in agreement with the results of $(9,12)$.

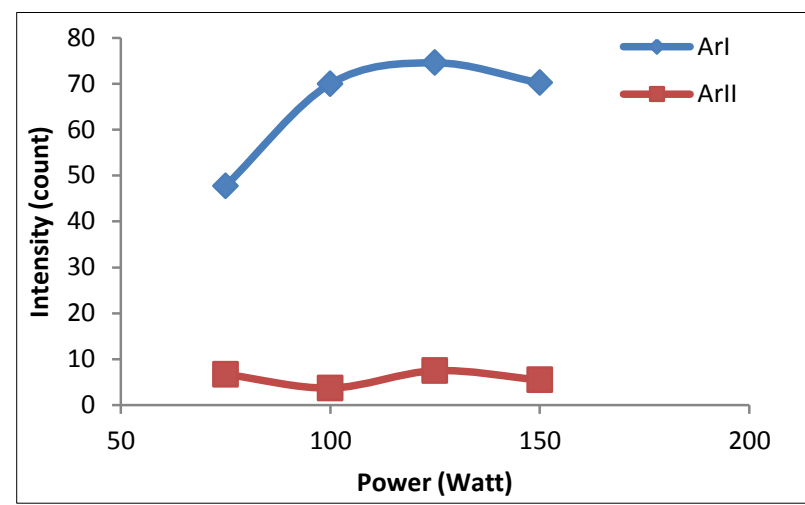

Figure 3. Variation of ArI $(750.37 \mathrm{~nm})$ and ArII $(434.5 \mathrm{~nm})$ lines intensity with $\mathrm{RF}$ power at $3 \times 10^{-2}$ torr.

Figure 4. shows the temperature variation is lower from (1.08 to $0.88 \mathrm{eV})$ and high to $1.01 \mathrm{eV}$ at 125 watt as a function of increasing energy. However, the decrease with the increase in energy that is expected to be the temperature of most electrons is more superior, which is observed to decrease with excess energy due to the transition $\alpha-\gamma$ The amplitude of the radio frequency with the wireless capability may increase by noting that there are usually two types of energy at the rate of discharge of radio frequencies capacitive; alpha and alpha modes. An indication of the $\alpha$ pattern in low voltage, in this pattern, the electrons in the plasma are initially questioned in order to stimulate excitation stimulation in the plasma. In increasing the great powers RF that meets in our experimental conditions, the. The mode is displayed. In this pattern, electrons are sent from electrode surfaces that play an important role in total ionization and excitation in the plasma. Therefore, with increased energy, strong secondary electrons will be sent from electrodes that improve ionization, which may increase in $T_{e}$. The deviation in plasma temperature causes a nonlinear change in the energy of the ions with increased power. In the figure below shows that the average ion energy reaches maximum RF power at about $75 \mathrm{~W}(11,13,14)$.

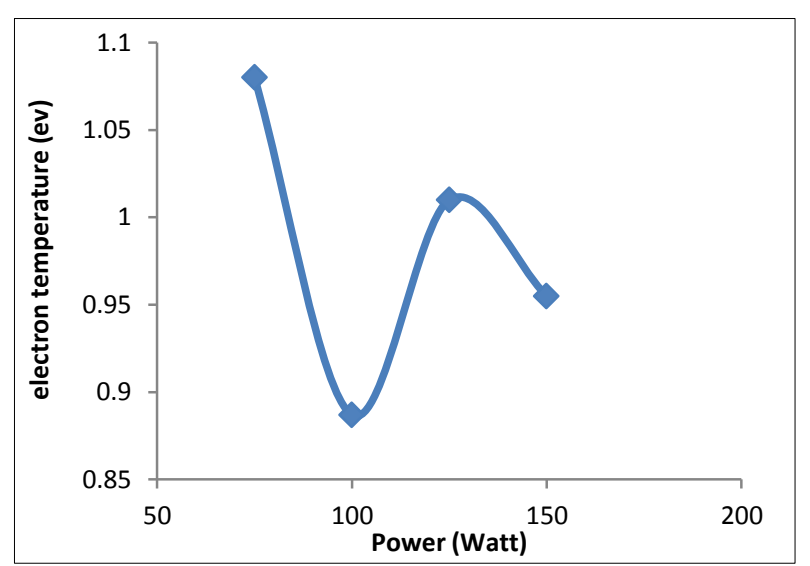

Figure 4. Effect of RF power on the electron temperature $(\mathrm{eV})$.

Figure 5. indicates the variation of electron density $\left(\mathrm{n}_{\mathrm{e}}\right)$ with RF power. This Figure shows that the electron density excess from( 3.03 to $\left.5.98 \mathrm{~cm}^{-3}\right)$ with increasing RF power. In turn, the increasing in RF power leads to excess the number of electrons emitted from the cathode, hence the increasing in the ionization processes leads to the excess density of electrons. In another way, the electron density lowered from (5.98 to $3.84 \mathrm{~cm}^{-3}$ ) with an excess of RF power. This behavior may be due to the losses of electrons with increasing of RF power (9). On the other hand the electron density excess, through the particle equilibrium been ions which generated by electron influence and ions missing on the source walls, it is maybe that the $\left(T_{e}\right)$ is independent of the $\left(\mathrm{n}_{\mathrm{e}}\right)$. So higher proceeds in RF power to an increase in electron density (15). 


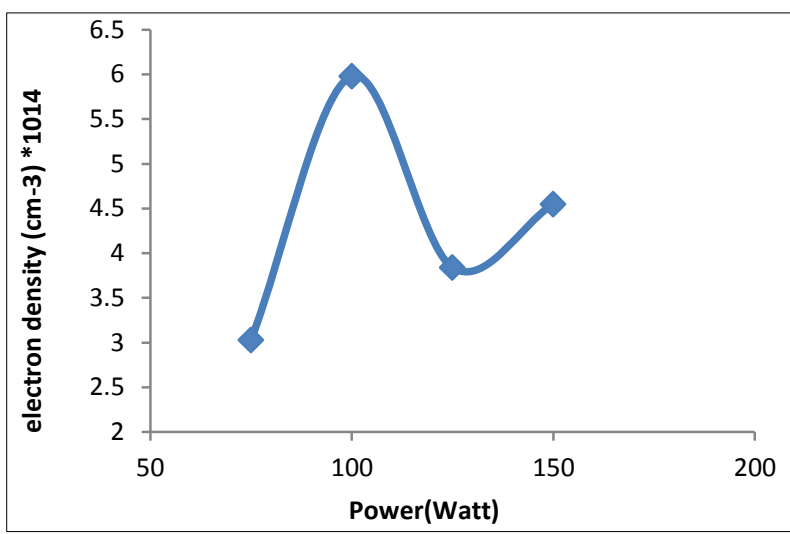

Figure 5. Effect of RF power on the electron density $\left(\mathrm{cm}^{-3}\right) * 10^{14}$.

The emission spectra of the plasma argon produce between electrodes at pressure $(0.03,0.05$ and 0.007$)$ torr are in Fig. 6. The intensity of the lines excess the invader pressure excess, where the intensity of the lines, found to be relative to $\mathrm{p}^{\alpha}$, where $\alpha$ is constant, which differs between $0.2-$ 0.5 , adopting on the wavelength (6). Considering $\mathrm{Ar}$ I line of wavelength $750.37 \mathrm{~nm}$ and ArII line with wavelength $434.5 \mathrm{~nm}$ by using NIST we get show the Table (1).

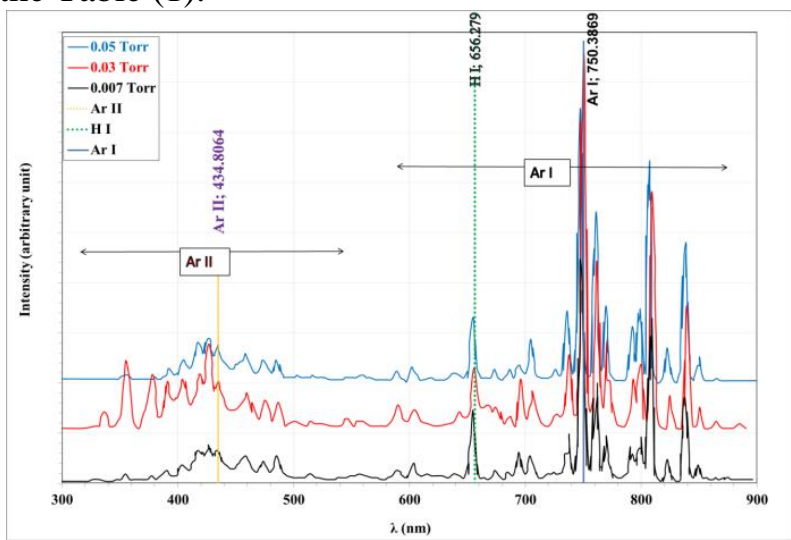

Figure 6. The emission spectra for plasma argon at different working pressures.

The change of the intensity of the special line as a function of working pressure is shown in Fig.7. The marked improvement in emission lines employed at $750.37 \mathrm{~nm}$ and $434.5 \mathrm{~nm}$ at ArI and ArII, individually. The observe that the intensified at the pressure 0.03 torr the intensity of (ArI) because of $\mathrm{Ar}$ emission intensity and energy of $\mathrm{Ar}$ ion. Then, the energetic Ar ions can increase the sputtering of from the target, which results in an increase the Ar sent out intensity. Energetic (Ar) ions can haunt an increasing in the secondary electrons sent out from the target, this effect which increase in the plasma intensity.

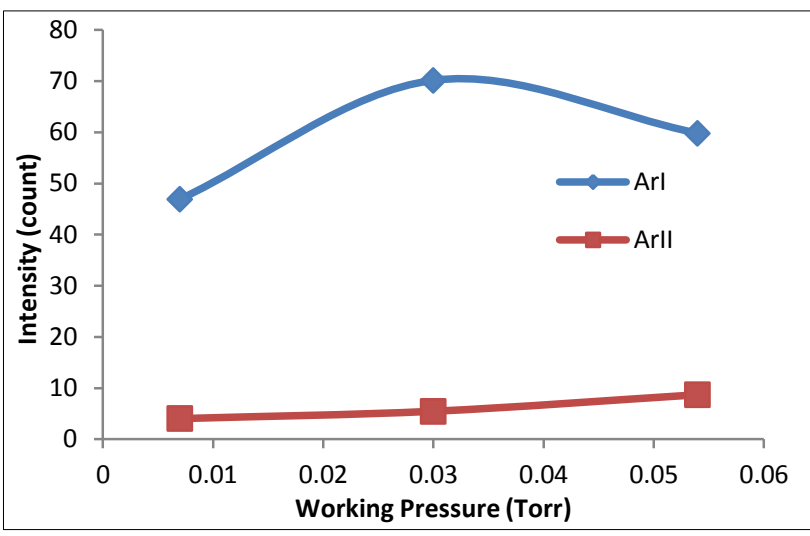

Figure 7. Effects of varying working pressure on Intensity.

Figure 8. shows the electron temperature (Te) decreased with increase working pressure, from $(0.007$ to 0.03$)$ torr, increasing pressure leads to a reduced average of the free path for electron collisions, so that electrons ionize to the atoms will be, then more frequently to give a higher plasma density, where electrons may easily lose their energy resulting in a reduced electron temperature, on other hand at pressure values increase the "Paschen minimum", stubborn collisions become more dominant resulting in a decreasing of plasma electron temperature. These results are in agreement with results of previous Study (16).

As it is observed that $T_{e}$ will increase linearly with increase pressure by increased electron impact. The $\mathrm{T}_{\mathrm{e}}$ was a measure to a little decrease from 0.97 to $0.95 \mathrm{eV}$ and increasing to $1.11 \mathrm{eV}$ with different working pressure. higher $\mathrm{T}_{e}$ with pressure is probably because of less electron scattering and as a result, less energy will be lost. The significantly decreased "electron temperature" decrease the ionization efficiency significantly. These results are in agreement with the results of reference (17).

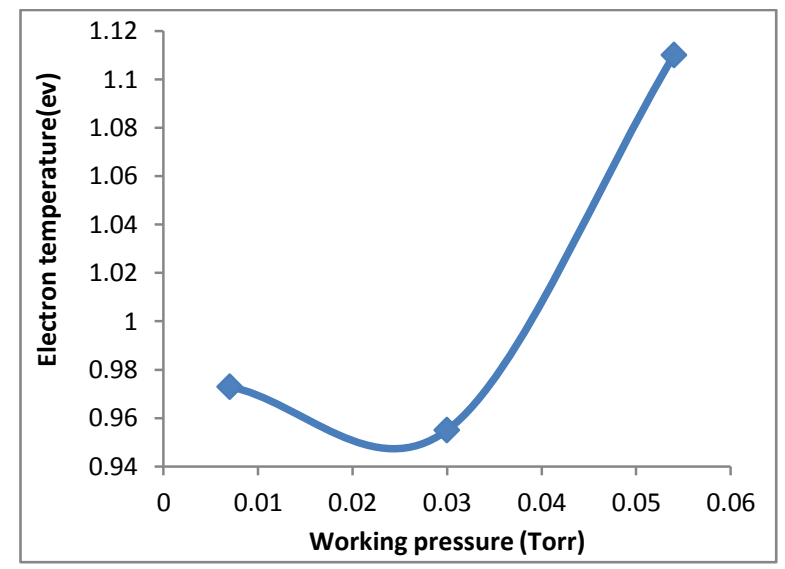

Figure 8. Effects of varying working pressure on $T_{e}(e V)$. 
Figure 9. shows the variation in operating pressure, which causes a difference in the collision rate without a change in plasma density. This occurs because the external discharge power is insufficient. So that more pairs can be produced and higher intensity at high pressure. The increase comes after changes, with a $150 \mathrm{~W}$ power value, the maximum energy value of 0.03 torr due to an increase in energy consumption at low-density values of 0.05 Torr. The maximum density $\left(4.55 \mathrm{~cm}^{3}\right)$ at $(0.03$ torr) is higher than the rest pressures.

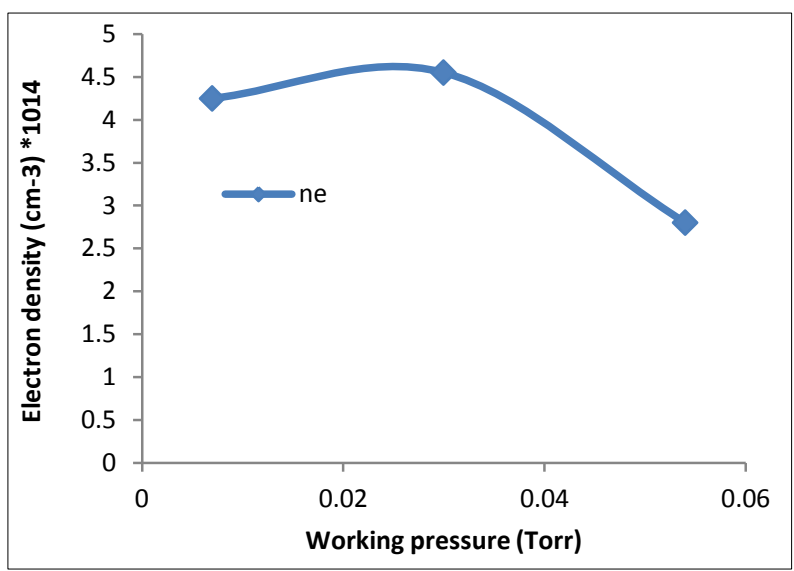

Figure 9. Effects of varying working pressure on $\mathrm{n}_{\mathrm{e}}\left(\mathrm{cm}^{-3}\right)$.

\section{Conclusions:}

In this study, the influence of working pressure and $\mathrm{RF}$ power on the plasma characterization is investigated for sputtering the $\mathrm{V}_{2} \mathrm{O}_{5}$ target. The optical emission spectroscopy (OES) device is used as a diagnostics device to plasma parameter in $\mathrm{RF}$ discharge. The results show that the increasing of RF power and pressure will increasing of lines intensity. As well as, the results show variation electron temperature low and up gradually increase with increasing of pressure and RF power. as will electron density decreases and increase with increasing RF power and pressure.

\section{Conflicts of Interest: None.}

\section{References}

1. Vašina P. Plasma diagnostics focused on new magnetron sputtering devices for thin film deposition. $\mathrm{PhD}$ [dissertation]. University in Brno, Department of Physical Electronics; 2005.

2. Koirala SP, Abu-Safe HH, Mensah SL, Naseem HA, Gordon MH. Langmuir probe and optical emission studies in a radio frequency (rf) magnetron plasma used for the deposition of hydrogenated amorphous silicon. Surf. Coating Technol. 2008;203(5-7):602-5.

3. Khalaf MK, Al-Taay HF, Ali DS. Effect of radio frequency magnetron sputtering power on structural and optical properties of Ti6Al4V thin films. Photonic Sensors. 2017;7(2):163-70.
4. Granqvist CG, Green SV, Li SY, Mlyuka NR, Niklasson GA, Avendaño E. Chromogenics for Sustainable Energy: Some Advances in Thermochromics and Electrochromics. Some Advances in Thermochromics and Electrochromics," Adv. Sci. Technol. 2010;7(5): 55-64.

5. Ottaviano L, Pennisi A, Simone F, Salvi AM. RF sputtered electrochromic $\mathrm{V}_{2} \mathrm{O}_{5}$ films. Opt. Mater. 2004;27(2):307-13.

6. Garamoon AA, Samir A, Elakshar FF, Nosair A, Kotp EF. Spectroscopic study of argon DC glow discharge. IEEE Trans. plasma Sci.. 2007;35(1):1.

7. Khan FU, Rehman NU, Naseer S, Naveed MA, Qayyum A, Khattak NA, Zakaullah M. Reply to comment on "Diagnostics of $13.56 \mathrm{MHz}$ RF sustained $\mathrm{Ar}-\mathrm{N}_{2}$ plasma by optical emission spectroscopy" by N. Sadeghi and FJ GordilloVazquez. Eur. Phys. J. Appl. Phys. 2009;47(1).

8. Naz MY, Ghaffar A, Rehman NU, Shahid SA, Shukrullah S. Characterization of an In-house Built $50 \mathrm{~Hz}$ Single Dielectric Barrier Discharge System Having Asymmetric Electrodes. Int. J. Eng. Technol. 2012;12(05):53-60.

9. Hassouba M, Dawood N. A Comparative Spectroscopic Study on Emission Characteristics of DC and RF Discharges Plasma using Different Gases. Life Sci. J. 2014;11(9):656-66.

10. National Institute of Standards and Technology (NIST) atomic spectra database, (ver.5.1). Available at http://www.nist.gov/pml/data/asd.cfm, last updated: November 2, 2015.

11. Kechkar S, Swift P, Kelly S, Kumar S, Daniels S, Turner M. Investigation of the electron kinetics in $\mathrm{O}_{2}$ capacitively coupled plasma with the use of a Langmuir probe. Plasma Sources Sci. Technol. 2017; 26(6):065009.

12. Belkind A, Zhu W, Lopez J, Becker K. Timeresolved optical emission spectroscopy during pulsed dc magnetron sputter deposition of $\mathrm{Ti}$ and $\mathrm{TiO}_{2}$ thin films. Plasma Sources Sci. Technol. 2006 Apr 24;15(2):S17.

13. Susana E, Felizardo E, Henriques J, Tatarova E, Dias F.M, Ferreira C.M. Experimental investigation of vacuum ultraviolet emissions in microwave argon plasmas: dependence on microwave power and discharge pressure. Inst. Plasmas Nucl. Fusion, Inst. Super. Técnico, Tech. Univ. Lisbon, 2015; 1049-001.

14. Wang D, Liu W, Wu Y, Hang L, Yu H, Jin N. Characteristics of plasma source for the plasma polishing of super smooth optics. Phys. Procedia. 2011; 1(19):412-5.

15. Barbisan M, Zaniol B, Cavenago M, Pasqualotto R, Serianni G, Zanini M. Electron density and temperature in NIO1 RF source operated in oxygen and argon. In AIP Conference Proceedings 2017; 18 (69): 030031.

16. Azooz AA, Cakir S, Bleej DA. Plasma parameters in $40 \mathrm{MHz}$ Argon discharge. Results Phys. 2015; 1(5):85-91.

17. Meng L. Plasma diagnostics and ITO film deposition by RF-assisted closed-field dual magnetron system. $\mathrm{PhD}$ [dissertation] University of Illinois; 2010. 


\section{التشخيص الطيفي للبلازما لمادة خامس اوكسيد الفاناديوم في الترذيذ الماكنتروني بالترددات الراديوية مع تغير طاقة التشغيل والضغ في الضئ}

هناء عيسى جاسم4

3

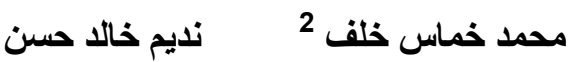

إبر اهيم خلف سلمان 1

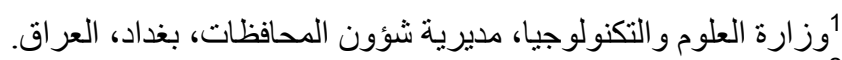

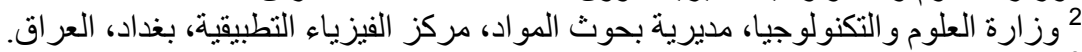

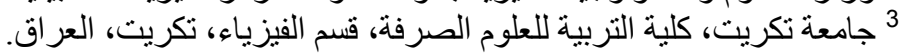

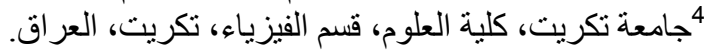

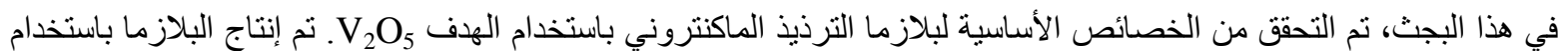

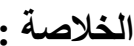

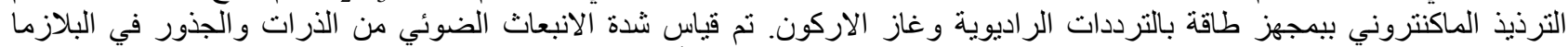

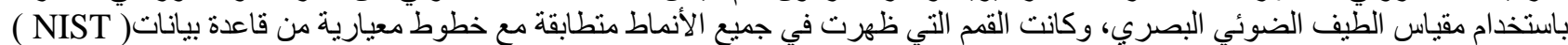

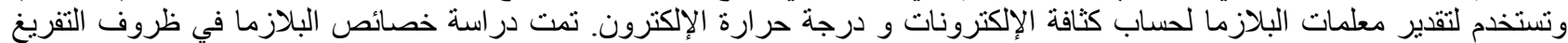

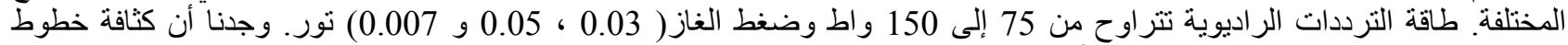

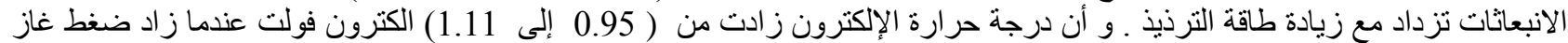

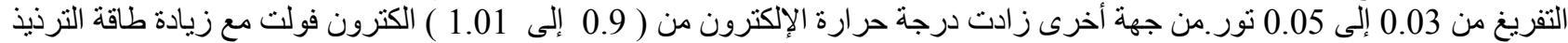

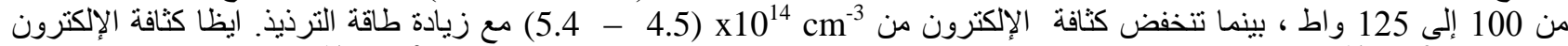

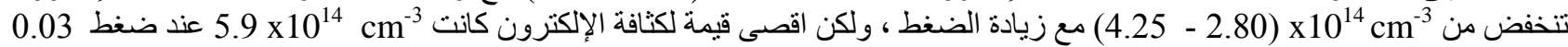
تور . تون من

الكلمات المفتاحية : طيف البلازما، خامس اوكسيد الفاناديوم، كثافة الاكترون، درجة حر ارة الإكترون، الترذيذ الماكنتروني . 